\title{
Hyposalivation Response to Low-Level Laser in Diabetic Type 2 Patients
}

\author{
SAFAA S.S. SHETAWY, M.Sc.*; HANY E. OBAYA, Ph.D.*; \\ FATMA ABOELMAGD M. HAMED, Ph.D.*,** and AHMED M. MOSAAD, M.D.*** \\ The Department of Physical Therapy for Cardiovascular/Respiratory Disorder and Geriatrics, Faculty of Physical Therapy, \\ Cairo University*, Faculty of Physical Therapy, Sinai University** and The Department of Internal Medicine, \\ Faculty of Medicine, Suez Canal University***
}

\begin{abstract}
Background: Diabetes mellitus is a chronic metabolic disorder, which usually leads to various complications. Among these complications is salivary hypofunction characterized by an abnormal reduction in saliva flow rate.

Aim of Study: The aim of this study was to find out the efficacy of LLLT on hyposalivation in diabetic type 2 patients.

Patients and Methods: Twenty-five diabetic type 2 patients from both sexes (16 females and 9 males) were included in the study. Their ages ranged from 40 to 55 years old. Patients were recruited from the outpatient clinic of internal medicine, Suez Canal hospital. All patients included in the study were with whole resting saliva $190.16 \mathrm{ml} / \mathrm{min}$. The study was conducted from August 2020 to March 2021. The salivary flow rate was measured using the 'low forced spitting' method. The collection period was $5 \mathrm{~min}$. The salivary flow rate $(\mathrm{ml} / \mathrm{min})$ was calculated by dividing the collected salivary amount (volume in $\mathrm{ml}$ ) by the time of collection period (5 minutes). The salivary flow rate was measured before starting of sessions (pretreatment), after the 6 th session (post I), and after the $12^{\text {th }}$ session (post II) in the same procedure. Patients were assigned into one experimental group received 12 sessions ( 2 sessions per week for 6 weeks) of low-level laser. LLLT was performed on the major salivary glands punctually. Three points were applied extraorally to each parotid gland, two to each submandibular gland, and two to each sublingual gland. A total of 14 points were applied per session. Application duration was $30 \mathrm{sec}$ per point (total duration of 14 points was $420 \mathrm{sec}$ ).
\end{abstract}

Results: There was a significant increase in salivary flow rate at the post I and post II compared with pretreatment $(p<0.001)$. The percent of change at the post I was $118.18 \%$ and at post II was $218.18 \%$. There was a significant increase in salivary flow rate at post II compared with post $\mathrm{I}(p<0.001)$ and the percentage of increase was $45.83 \%$.

Conclusion: These results suggested that LLLT had a hopeful effective role in improving hyposalivation related to diabetic complications.

Key Words: Hyposalivation - Xerostomia - Dry mouth - Lowlevel laser (LLL) - Type 2 diabetes mellitus.

Correspondence to: Dr. Safaa S.S. Shetawy,

E-Mail: safaasalem268@gmail.com

\section{Introduction}

DIABETES mellitus (DM) is a chronic disease associated with hyperglycemia and caused by total or partial insulin insufficiency. DM has become a worldwide public health problem. According to the growing morbidity in recent years, by 2040 , the world's diabetic patients will rise to 642 million, which means that in the future one of the ten adults will suffer from diabetes [1].

DM can cause serious dysfunction and damage to various organs, especially the eyes, heart, kidneys, blood vessels, and nerves [2]. Due to the negative impacts of diabetes mellitus on the sympathetic and parasympathetic nervous system, dehydration, microangiopathy, and hormonal changes, it may result in discrepancies in the salivary flow rate with marked salivary hypofunction [3].

Hyposalivation is one of the main problems caused due to the altered flow rate of stimulated and unstimulated whole saliva in type II diabetic patients. In addition, diabetic patients usually have a higher concentration of glucose, calcium, and urea, which leads to several oral diseases, as xerostomia and oral lesions [4]. Xerostomia is defined as the subjective sensation of dry mouth caused due to the reduction or absent salivary secretions while hyposalivation is an objective sign of saliva reduction [5]. The average unstimulated salivary flow rate of a normal adult ranges from $0.1-0.5 \mathrm{ml} /$ min while the stimulated flow rate was found to be higher, $1-2 \mathrm{ml} / \mathrm{min}$ [6]. It is estimated that an unstimulated salivary flow rate $<0.16 \mathrm{ml} / \mathrm{min}$ is considered hyposalivation [7]. 
Dry mouth has been associated with several oral and general symptoms, such as difficulty in swallowing, speech disorders, difficulty in eating dry food, alteration of taste, waking at night to drink water, and repetitive need to drink water during the day [23]. In addition, Hyposalivation can cause many oral disorders such as dental caries, gingivitis, and mastication problems. In turn, these disorders eventually will decrease oral healthrelated quality of life [5].

Management of hyposalivation using salivary substitutes and pharmacologic methods has side effects such as profuse sweating, urinary frequency, rhinitis, and dyspepsia [7]. There is no completely effective treatment for xerostomia and hyposalivation [8]. Therefore, future development of alternative treatment strategies is highly required [9].

Low-level laser therapy (LLLT) is a device known for its wound healing properties due to the stimulation of cellular processes, such as proliferation, migration, and differentiation. Previous studies proved that low-level laser therapy (LLLT) is effective in the treatment of diseases and various conditions by stimulating biomodulation in the cellular metabolism of the tissue to be repaired. It also has anti-inflammatory and analgesic effects [10].

Depending on these beneficial effects, LLLT has been used as a salivary stimulant in patients with conditions and diseases that involve a decreased salivary flow rate [11]. Therefore, the aim of this study was to determine the efficacy of lowlevel laser therapy (LLLT) on hyposalivation in type $2 \mathrm{DM}$.

\section{Material and Methods}

\section{Subjects and study design:}

Subjects:

Twenty-five diabetic type 2 patients from both sexes ( 16 females and 9 males) were recruited from the outpatient clinic of internal medicine, Suez Canal hospital to participate in the study; their ages were from 40-55 years old. All patients included in the study were with whole resting saliva $\leq 0.16 \mathrm{ml} / \mathrm{min}$ [7]. The study was conducted in the Outpatient Clinic of Internal Medicine Suez Canal hospital, Ismailia; from August 2020 to March 2021. All the procedures of the study were approved by the Ethical Committee for Scientific Researches of Faculty of Physical Therapy, Cairo University with approval number (P.T.REC/ 012/002770). All participated patients in the study were non-smokers, non-alcoholic, and diagnosed diabetics with fasting blood glucose level $\geq 126 \mathrm{mg} /$ $\mathrm{dl}$ or currently taking diabetic medications. Excluded patients by the physician were pregnant females, cardiac and cancer ones, patients undergoing medical management for xerostomia, patients with neurological disorders (Parkinson's disease, stroke, epilepsy, and Bell's palsy), endocrine diseases, salivary gland diseases, Chronic inflammatory autoimmune disease, and acute oral inflammatory disorders.

\section{Evaluated parameters:}

\section{Salivary flow rate assessment:}

The salivary collection was performed between 9 and $11 \mathrm{am}$. Patients were asked to refrain from eating, chewing gum, and drinking for 2 hours before the test session, to avoid swallowing, and to make as few movements as possible during the procedure. To collect whole resting saliva, patient's arms relaxed over their knees while lowering heads and facing slightly forward over the graduated test tube to collect the saliva in the anterior region of the mouth floor. Maintaining little body movement and or facial movements, patients spit into the test tube using 'low forced spitting' movement. The collection period was $5 \mathrm{~min}$. The salivary liquid component, not the foam, only was measured. The salivary flow rate $(\mathrm{ml} / \mathrm{min})$ was calculated by dividing the collected salivary amount (volume in $\mathrm{ml}$ ) by the time of collection period (5 minutes). The salivary flow rate was measured before starting of sessions (pretreatment), after the 6th session (post I), and after the 12 th session (post II) in the same procedure. An increased post-treatment whole salivary flow rate than pre-treatment whole salivary flow rate was considered an improvement in the study.

\section{Low-level laser therapy protocol:}

Patients were assigned into one experimental group received 12 sessions ( 2 sessions per week for 6 weeks) of low-level laser by (EME PHYSIO LIS 1050: LT1370, made in Italy). The following parameters were used: $905 \mathrm{~nm}$ wavelength, $100 \mathrm{~mW}$ output power, $3.57 \mathrm{~W} / \mathrm{cm}^{2}$ power density, $71 \mathrm{~J} / \mathrm{cm}^{2}$ doses per point, $2 \mathrm{~J}$ energy per point, application time $30 \mathrm{sec}$ per point, and $28 \mathrm{~J}$ dose per session. LLLT was performed on the major salivary glands punctually. Three points were applied extraorally to each parotid gland, two to each submandibular gland, and two to each sublingual gland. A total of 14 points were applied per session. Application time was 30sec per point (total duration of 14 points was $420 \mathrm{sec}$ ). The tip of the tool remained in contact with and perpendicular to the patients' skin during the applications (extraoral). 


\section{Statistical analysis:}

Descriptive statistics were conducted for the subject characteristics. Normal distribution of data was checked using the Shapiro-Wilk test. ANOVA with repeated measures test was conducted for comparison between pre, post 1 , and post II measurements of salivary flow rate. The level of significance for all statistical tests was set at $p<0.05$. All statistical tests were performed through the statistical package for social studies (SPSS) version 25 for windows. (IBM SPSS, Chicago, IL, USA).

\section{Results}

\section{Participant characteristics:}

Table (1) showed the participant characteristics of the study group.

Table (1): Basic characteristics of participants.

\begin{tabular}{ll}
\hline & Study group \\
\hline Age, mean $\pm(\mathrm{SD})$, years & $49.08 \pm 4.37$ \\
Weight, mean $\pm(\mathrm{SD}), \mathrm{kg}$ & $82.08 \pm 14.48$ \\
Height, mean $\pm(\mathrm{SD}), \mathrm{cm}$ & $165.72 \pm 8.28$ \\
BMI, mean $\pm(\mathrm{SD}), \mathrm{kg} / \mathrm{m}^{2}$ & $29.81 \pm 4.41$ \\
Sex, $n(\%):$ & \\
$\quad$ Females & $16(64 \%)$ \\
$\quad$ Males & $9(36 \%)$ \\
\hline
\end{tabular}

SD: Standard deviation.

\section{Effect of treatment on salivary:}

There was a significant increase in salivary flow rate at post I and post II compared with pretreatment $(p<0.001)$. The percent of change at post I was $118.18 \%$ and at post II was $218.18 \%$.

There was a significant increase in salivary flow rate at post II compared with post I $(p<0.001)$ and the percentage of increase was $45.83 \%$. (Table 2).

Table (2): Mean salivary flow rate at pre-treatment, post I, and post II.

\begin{tabular}{llll}
\hline $\begin{array}{l}\text { Salivary flow rate } \\
(\mathrm{ml} / \mathrm{min})\end{array}$ & $\begin{array}{c}\text { Pre-treatment } \\
\text { Mean } \pm \text { SD }\end{array}$ & $\begin{array}{c}\text { Post I } \\
\text { Mean } \pm \text { SD }\end{array}$ & $\begin{array}{c}\text { Post II } \\
\text { Mean } \pm \text { SD }\end{array}$ \\
\hline & $0.11 \pm 0.04$ & $0.24 \pm 0.08$ & $0.35 \pm 0.06$ \\
\hline & MD & $\%$ of change & $p$-value \\
\hline $\begin{array}{l}\text { Multiple comparisons } \\
\text { (Bonferroni test): }\end{array}$ & & & \\
Pre Vs Post I & -0.13 & 118.18 & 0.001 \\
Pre Vs Post II & -0.24 & 218.18 & 0.001 \\
Post I Vs Post II & -0.11 & 45.83 & 0.001 \\
\hline
\end{tabular}

SD : Standard deviation.

MD: Mean difference.

$p$-value: Level of significance.

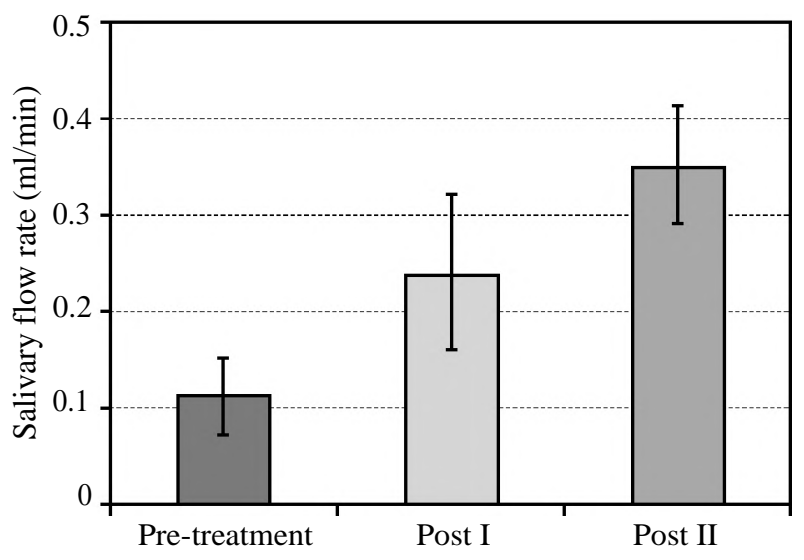

Fig. (1): Mean salivary flow rate at pretreatment, post I, and post II.

\section{Discussion}

Diabetes is commonly accompanied by dysfunction of salivary glands causing salivary hypofunction or xerostomia [12]. This condition may result in other problems (e.g., difficulty in eating, swallowing, and speaking, constant sore throat, changes in the sense of taste, burning sensation, oral pain, dental caries, and frequent difficulties in the use of dental prosthetics [13].

Therefore, the aim of the current study was to find out the impact of LLLT on hyposalivation in type 2 diabetics. Analysis of the results of the present study indicated that application of extraoral LLLT on bilateral major salivary glands led to a highly significant improvement in salivary volume and flow rate after 6 sessions and after 12 sessions measurements compared to pretreatment with percent of change $118.18 \%, 218.18 \%$ respectively. Comparing post I (after 6 sessions) to post II (after 12 sessions) measurements showed that there is a positive continuous effect of LLLT with increasing the number of sessions until the 12 th session as the percentage of increase was $45.83 \%$.

Until now, the exact mechanism of positive efficacy of low-level laser on salivary glands stimulation remains poorly understood [8]. It has been estimated that the effect produced by LLLT is based on its capacity to modulate various metabolic processes, by conversion of the laser energy through biochemical and photophysical processes, which transform the laser light into energy useful to the cell. Visible laser energy is absorbed by chromophores in the respiratory chain of the mitochondria, with an increase in ATP production, which results in increased cellular proliferation and protein synthesis, aiding tissue repair [14] . Among the effects of LLLT, it has a deeply analgesic effect, can promote cellular biomodulation, collagen syn- 
thesis, fibroblast proliferation, and tissue regeneration [15].

Regarding xerostomia, LLLT produces gland regeneration, improved salivary flow, and secretions, improved antimicrobial characteristics, and reduction of orofacial pain [13]. Sato et al., [16] supposed that LLLT leads to stimulation of lingual nerve that supplies salivary glands causing rapid increases in glandular blood flow and induced salivary secretion from the three glands in both diabetic and nondiabetic rats.

Pavlic', [17] stated that in all published articles, which were considered adequate for this overview, positive effects of low-level laser therapy were reported. Low-level laser therapy could significantly enhance salivary secretion and improve antimicrobial characteristics of secreted saliva. Furthermore, low-level laser therapy could improve salivary flow and regeneration of salivary duct epithelial cells.

The literature on LLLT for the management of hyposalivation in DM is limited. A study was done by González et al., [18] involving a variety of noncancer patients with xerostomia, LLLT was applied daily: Extraorally to the parotid and submandibular glands and intraorally on the sublingual glands. A gradual increase in the stimulated salivary flow was found after LLLT compared to controls. Similar results in noncancer patients were reported by [19].

Simões et al., [20] made a clinical case study report on dry mouth symptoms in a patient with Sjogren's syndrome using LLLT. The salivary flow rate and xerostomia symptoms were measured before, during, and after LLLT treatment. Dry mouth symptoms improved during LLLT. In their study, they found that the incidence of xerostomia is significantly reduced in patients treated with LLLT.

In addition, the use of low-level laser therapy on salivary glands in the treatment of xerostomia has proved to be not only stimulative but also regenerative in nature [21].

Previous studies on experimental animal models demonstrate the diverse effects of LLLT on salivary glands. It was shown that LLLT stimulates mitotic activity in the epithelial tissue of murine salivary glands, increases the salivary flow rate, changes enzymatic activity levels in saliva, and alters salivary protein concentration. Most of the previously published studies refer to investigations into the effect of low-power lasers on structural and cyto- chemical alterations in animal salivary glands, while only a small number of clinical cases have been reported [22].

Therefore, our present study's findings confirm the results of similar studies and support the idea that LLLT could affect salivary hypofunction promoting significant increase in salivary flow rate. As a result, an evident improvement in quality of life could be achieved.

\section{Conclusion:}

Based on the results of the current study, it was concluded that LLLT had a hopeful effective role in improving hyposalivation related to diabetic complications.

\section{References}

1- ZOU Q., QU K., LUO Y., YIN D., JU Y. and TANG H.: Predicting diabetes mellitus with machine learning techniques. Frontiers in Genetics, 9: 515, 2018.

2- MANIRUZZAMAN M., RAHMAN M.J., AHAMMED B. and ABEDIN M.M.: Classification and prediction of diabetes disease using machine learning paradigm. Health Information Science and Systems, 8 (1): 7. https:// . doi.org/10.1007/s13755-019-0095-Z, 2020.

3- SRIVASTAVA A., PADMAVATHI B.N., SHRIVASTAVA R., SRIVASTAVA R. and MATHUR S.: Study of salivary flow rate in type II diabetics: A case-control study. Journal of Indian Academy of Oral Medicine and Radiology, 30 (4): 372, 2018.

4- UTHAYASANKAR D. and JAYARAJ G.: Saliva in diabetes-a review. European Journal of Molecular \& Clinical Medicine, 7 (1): 1395-1403, 2020.

5- AGUSTINA D., CHRISMAWATY B.E. and HANINDRIYO L.: Hyposalivation is the main risk factor for poor oral health status in Indonesian elderly. Journal of International Oral Health, 13 (1): 60, 2021.

6- OYETOLA E.O., ABIMBOLA T.A., ADESINA O.M., EGUNJOBI S.M. and ADEBAYO O.F.: Clinical Oral Findings and Salivary Analysis of Patients with and Without Diabetes Mellitus. J. Oral Biol., 6 (2): 6, 2019.

7- ISMAIL A., EL-DIN H., MOHAMED M. and AAL1 M.: Impact of transcutaneous electrical nerve stimulation (TENS) on hyposalivation in type 2 diabetics. Bioscience Research, 16: 690-694, 2019.

8- PALMA L.F., GONNELLI F.A.S., MARCUCCI M., DIAS R.S., GIORDANI A.J., SEGRETO R.A. and SEGRETO H.R.C.: Impact of low-level laser therapy on hyposalivation, salivary $\mathrm{pH}$, and quality of life in head and neck cancer patients post-radiotherapy. Lasers in Medical Science, 32 (4): 827-832, 2017.

9- EPSTEIN J.B. and BEIER J.S.: Management of hyposalivation and xerostomia: Criteria for treatment strategies. Compend Contin Educ Dent, 36 (8): 600-603, 2015.

10- BAMPS M., DOK R. and NUYTS S.: Low-level laser therapy stimulates proliferation in head and neck squamous cell carcinoma cells. Frontiers in Oncology, 8: 343, 2018. 
11- FIDELIX T., CZAPKOWSKI A., AZJEN S., ANDRIOLO A., NETO P.H. and TREVISANI V.: Low-level laser therapy for xerostomia in primary Sjögren's syndrome: A randomized trial. Clinical Rheumatology, 37 (3): 729 736,2018

12- XIANG R., HUANG Y., ZHANG Y., CONG X., ZHANG Z., WU L. and YU G.: Type 2 diabetes? induced hyposalivation of the submandibular gland through PINK1/Parkin? mediated mitophagy. Journal of Cellular Physiology, 235 (1): 232-244, 2020.

13- ALFAYA T.A., CARVALHO P.A., TANNURE P.N., KALIL M.P., DOS SANTOS SPEDINI C.C., de GODOY C.H. and BUSSADORI S.K.: Sjogren's syndrome: Use of a low-level laser for treatment of xerostomia. Clin. Exp. Med. Lett., 53: 197-200, 2012.

14- CAMPOS L., SIMÕES A., SÁ P.H. and EDUARDO C.D.: Improvement in quality of life of an oncological patient by laser phototherapy. Photomedicine and Laser Surgery, 27 (2): 371-374, 2009

15- VARELLIS M.L., GONÇALVES M.L., PAVESI V.C., HORLIANA A.C., da SILVA D. de F.T., MOTTA L.J., BARBOSA FILHO V.F., BEZERRA C.D.S., da SILVA F.G., \& BUSSADORI S.K.: Evaluation of photobiomodulation in salivary production of patients with xerostomy induced by anti-hypertensive drugs: Study protocol clinical trial (SPIRIT compliant). Medicine, 99 (16), 2020.

16- SATO T., MITO K. and ISHII H.: Relationship between impaired parasympathetic vasodilation and hyposalivation in parotid glands associated with type 2 diabetes mellitus. American Journal of Physiology-Regulatory, Integrative and Comparative Physiology, 318 (5): R940-R949, 2020.

17- PAVLIC' V.: The effects of low-level laser therapy on xerostomia (mouth dryness). Medicinski Pregled, 65 (56): 247-250, 2012

18- GONZÁLEZ-ARRIAGADA W.A., RAMOS L.M.A., ANDRADE M.A. and LOPES M.A.: Efficacy of lowlevel laser therapy as an auxiliary tool for management of acute side effects of head and neck radiotherapy. Journal of Cosmetic and Laser Therapy, 20 (2): 117-122, 2018.

19- VIDOVIC' JURAS D., LUKAC J., CEKIC-ARAMBAS IN A., VIDOVIC' A., CANJUGA I., SIKORA M., CAREK A. and LEDINSKY M.: Effects of low-level laser treatment on mouth dryness. Collegium Antropologicum, 34 (3): 1039-1043, 2010.

20- SIMÕES A., EDUARDO F.P., LUIZ A.C., CAMPOS L., SÁ P.H., CRISTÓFARO M., MARQUES M.M. and EDUARDO C.P.: Laser phototherapy as topical prophylaxis against head and neck cancer radiotherapy-induced oral mucositis: Comparison between low and high/low power lasers. Lasers in Surgery and Medicine: The Official Journal of the American Society for Laser Medicine and Surgery, 41 (4): 264-270, 2009.

21- AKSHAYA R.: Xerostomia-A review. International Journal of Science and Research, 6 (2): 814-817, 2017.

22- LONCAR B., MRAVAK STIPETIC' M., BARICEVIC M. and RISOVIC' D.: The effect of low-level laser therapy on salivary glands in patients with xerostomia. Photomedicine and Laser Surgery, 29 (3): 171-175, 2011.

23- LONE M.A., SHAIKH S., LONE M.M., AFAQ A. and LONE M. A.: Association of salivary gland hypofunction with diabetes mellitus and drugs among the elderly in Karachi, Pakistan. Journal of Investigative and Clinical Dentistry, 8 (2): e12209, 2017.

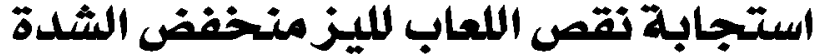

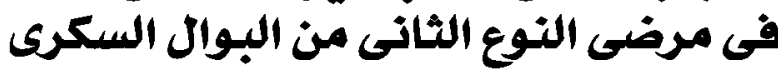

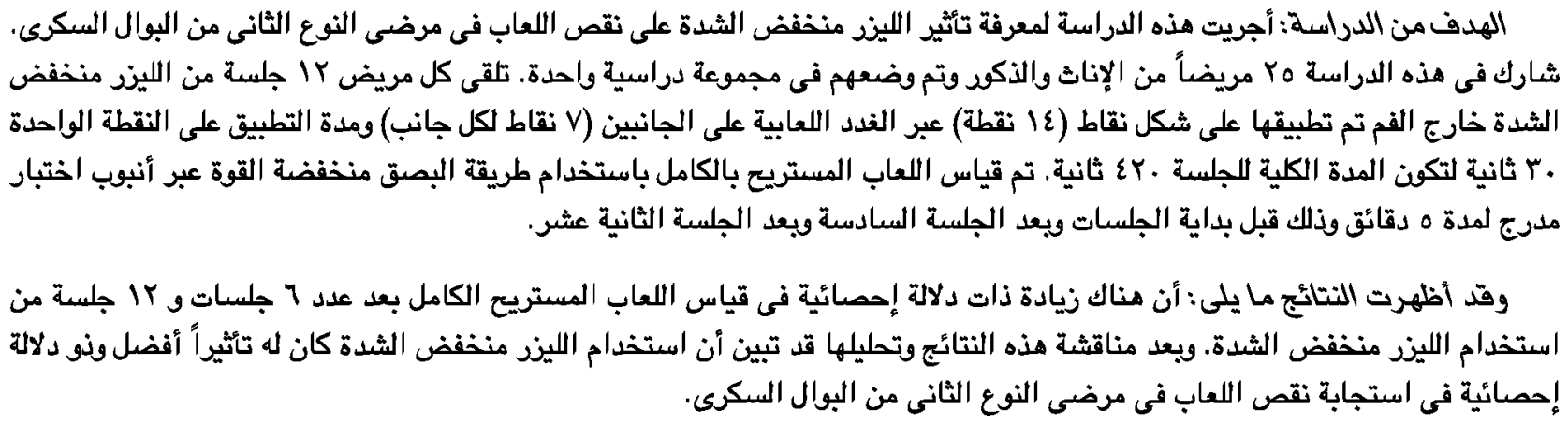

